\title{
INOVAÇÕES TECNOLÓGICAS NA CONSTRUÇÃO CIVIL
}

\section{ARTIGO DE REVISÃO}

CECÍLIO, Ana Beatriz Garcia Amaral ${ }^{1}$

FERNANDES, Matheus Luis ${ }^{2}$

FERNANDES NETO, Marcolino ${ }^{3}$

ORRÚ, Alice Perucchetti ${ }^{4}$

CARVALHO, Rogério de Souza ${ }^{5}$

CECÍLIO, Ana Beatriz Garcia Amaral. Et al. Inovações tecnológicas na construção civil. Revista Científica Multidisciplinar Núcleo do Conhecimento. Ano 05, Ed. 12, Vol. 10, pp. 54-71. Dezembro de 2020. ISSN: 2448-0959, Link de acesso: https://www.nucleodoconhecimento.com.br/engenharia-civil/inovacoestecnologicas

\section{RESUMO}

Este artigo tem como abordagem análises de inovações tecnológicas como elemento integrado na construção civil, a fim de aferir os benefícios que as tecnologias podem acrescentar ao setor da indústria imobiliária. Partindo, então, desse panorama o artigo estabelece uma discussão sobre a vantagem, contribuição e economia que a alta

\footnotetext{
${ }^{1}$ Graduação em Engenharia Civil.

${ }^{2}$ Graduação em Engenharia Civil.

${ }^{3}$ Doutorado em Engenharia Mecânica. Mestrado em Engenharia Metalúrgica e de Minas. Graduação em Engenharia Civil. Graduação em Engenharia Metalúrgica.

${ }^{4}$ Doutorado em Ciências Da Linguagem. Mestrado em Letras. Graduação em letrastradutor.

${ }^{5}$ Orientador.
} 
tecnologia pode oferecer às empresas e aos contratantes do empreendimento, deixando de ser apenas uma ferramenta de suporte para uma revolução intrínseca no setor da construção civil. No referencial teórico trata-se a tardia entrada do Brasil no desenvolvimento tecnológico e a grande competição no mercado da construção em busca de melhorias, a fim de apresentar as atuais tecnologias de ponta no segmento e um estudo analítico realizado para cada inovação tecnológica descrita. Os resultados discutidos através de análises comparativas do conteúdo apresentam os desafios e benefícios na projeção da engenharia civil, em utilizar e adequar as novas tecnologias que o mercado de trabalho disponibiliza, a fim de competir por mão de obra qualificada e qualidade nos empreendimentos. Finalmente considera-se a importância de inovar na indústria civil e as futuras expectativas em inovar no mercado de trabalho.

Palavras-chave: Alta Tecnologia, Construção Civil, Engenharia Civil, Inovações.

\section{INTRODUÇÃO}

Segundo dados do IBGE (2020), o ramo da Construção Civil, no Brasil, teve um crescimento demonstrativo no PIB (Produto Interno Bruto) de 1,6\% em comparação ao ano de 2018, impactando fortemente na saída do vermelho que o país se posicionou a 5 anos.

Uma pesquisa realizada pela Autodesk (2020), alerta que, mesmo com o crescimento da economia construtiva, o Brasil é o país com menor nível de maturidade tecnológica na indústria civil mundial e a falta de recursos tecnológicos prejudica a produtividade da construção civil.

No entanto, a Autodesk (2020) afirma que o Brasil é líder em investimentos de plataformas baseadas em BIM (Building Information Modeling), ferramenta integrada e eficiente para organização de detalhes e informações essenciais da construção. 
O CEO da Building Connected, Dustin DeVan (GALO, 2020), afirma que para maior produtividade da construção civil, é necessário que as empresas abracem o mundo digital como alternativa essencial para o desenvolvimento de infraestrutura imobiliária.

Este trabalho traz em seu desenvolvimento um estudo da aplicação de novas tecnologias e mensura os benefícios que os seguintes itens podem trazer à Construção Civil: novas tecnologias em plataformas de softwares, dispositivos avançados em canteiros verdes, drones e a ascensão da realidade aumentada.

Segundo a Techne (2012), o uso da tecnologia demonstra positividade no desenvolvimento de processos e produtos. Com o decorrer do tempo, empresas construtivas têm-se adaptado ao uso de novos equipamentos tecnológicos, porém, não basta somente o uso desses recursos tecnológicos se não houver um modelo eficiente de gestão da informação, integrando-o com os dispositivos e usuários capacitados, pois cada canteiro de obra tem suas necessidades específicas.

O estudo de inovação tecnológica na construção civil é de extrema importância para o mercado. A tecnologia está presente em todos os segmentos e não seria diferente na construção civil. Com a utilização inteligente dos recursos tecnológicos proporciona-se resultados significativos nas elaborações das obras.

\section{OBJETIVOS}

\subsection{OBJETIVO GERAL}

O presente trabalho tem como objetivo discutir as tecnologias atuais no mercado de trabalho na área da construção civil, demonstrando novos cenários para a construção no que se diz respeito aos processos das etapas da edificação com base na inserção de tecnologia para melhoria da gestão, design e projeção do empreendimento.

\subsection{OBJETIVOS ESPECÍFICOS}

- Analisar tecnologias existentes no mercado atual; 
- Identificar o perfil de cada tecnologia existente;

- Identificar a ação positiva da tecnologia em meios ambientais;

- Analisar a percepção da tecnologia no futuro.

\section{METODOLOGIA}

O estudo caracteriza-se como processo descritivo e de abordagem sistemática, com fisionomia exploratória, baseando-se em bibliografias, artigos científicos, revistas especializadas e sites de pesquisas sobre Tecnologias na Construção Civil. De acordo com Boccato (2006), a pesquisa bibliográfica tem como ênfase resolução de problemas, através de referenciais teóricos publicados, para analisar e discutir as possíveis soluções de determinado tema.

A fim de seguir o conceito descrito acima, o presente artigo utilizou como metodologia, como base no referencial teórico, comparações de atividades realizadas na construção civil sem e com a inserção de tecnologia para melhorar e agilizar o andamento das obras, possíveis aplicações futuras, com evidências na viabilidade dentro do ramo imobiliário. Finalmente, apresentam-se os resultados e discussões finais sobre a repercussão da tecnologia na construção civil.

\section{REFERENCIAL TEÓRICO}

\subsection{TECNOLOGIAS EM CANTEIROS DE OBRAS}

Souza et. al. (2013) afirmam que o canteiro de obras compõe-se por elementos que contribuem, de forma direta ou indiretamente, a execução da edificação. Contudo, a realização da projeção de um canteiro de obras requer considerá-lo não apenas como um conjunto de elementos estáticos postos corretamente, mas também como um processo dinâmico e complexo.

Segundo Pereira e Alencar (2019), a maior parte das empresas procura como meta aumentar sua produtividade nas obras para diminuir custos e despesas, através de 
alternativas tecnológicas avançadas na construção civil. Consequentemente estes recursos geram maior eficiência das construtoras e rapidez nos processos construtivos.

Mercado e Kullok (2004), afirma que a era digital mudou totalmente o campo da engenharia, encurtando a distância entre as obras, os engenheiros e os proprietários, integrando-os através de computador como principal fonte de globalização econômica.

De acordo com Zaparolli (2019), a construção civil brasileira, mesmo que atrasada mundialmente, finalmente dá início a incorporar tendências tecnológicas do mercado digital, onde em outros setores seu desenvolvimento já é frequente. Assim projetos formulados em ambientes digitais que permitem o controle das obras e funcionários, tornaram-se ferramentas que começam a entrar com força nos canteiros de obras à partir de 2019.

\subsection{THE GUARDIAN XO}

Segundo Balwin (2020), com tantos avanços tecnológicos, a empresa norteamericana de robótica Sarcos, especializada em dispositivos militares e segurança nacional, desenvolveu um exoesqueleto de corpo inteiro, chamado The Guardian XO, que permite, aos trabalhadores da construção civil, carregarem massas de até $90 \mathrm{Kg}$ por longos espaços de tempo, no intuito de diminuir estresses físicos.

A Figura 1 mostra o dispositivo robótico que permite que os trabalhadores carreguem aproximadamente $90 \mathrm{Kg}$ por longos períodos de tempo. 
Figura 1: The Guardian XO da empresa SARCOS

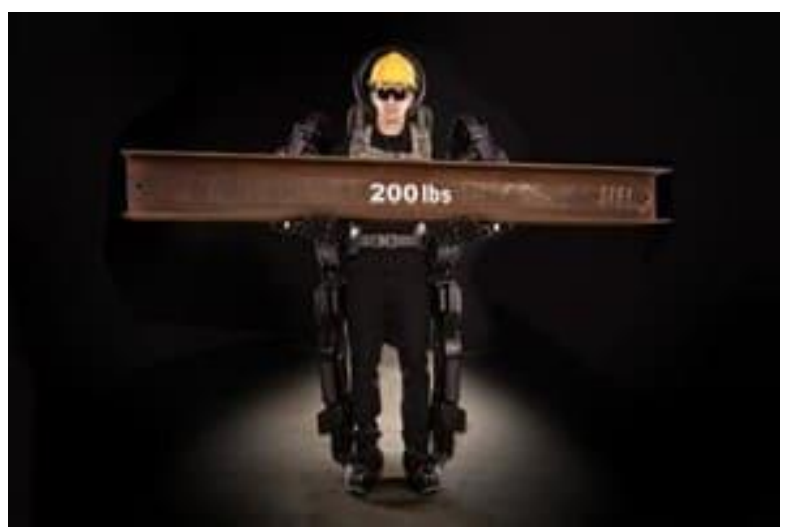

Fonte: Balwin (2020)

De acordo com a NR 17.2.2 (2018), não deverá ser exigido nem admitido o transporte manual de cargas, por um trabalhador cujo peso seja suscetível de comprometer sua saúde ou sua segurança (117.001-5 / 11).

\subsection{BIM - BUILDING INFORMATION MODELING}

Conforme Zaparolli (2019), a plataforma BIM atualmente é uma das ferramentas mais utilizadas por engenheiros civis, ela facilita a convergência de projetos, como as partes de elétrica, hidráulica, fundações, disposição de ambientes e arquitetura da obra. Além de contribuir para melhorar a performance do projeto, o BIM também proporciona eficiência na elaboração de um canteiro de obras, dando uma abertura maior para mais informações, segurança e agilidade nos processos.

Segundo Zaparollli (2019), a plataforma além de auxiliar na formulação do corpo do canteiro, também colabora para a comunicação dos funcionários da obra com o pessoal do escritório em tempo real. A Figura 2 mostra os programas da plataforma BIM que podem ser utilizados. 
Figura 2: Programas da plataforma BIM podem ser utilizados.

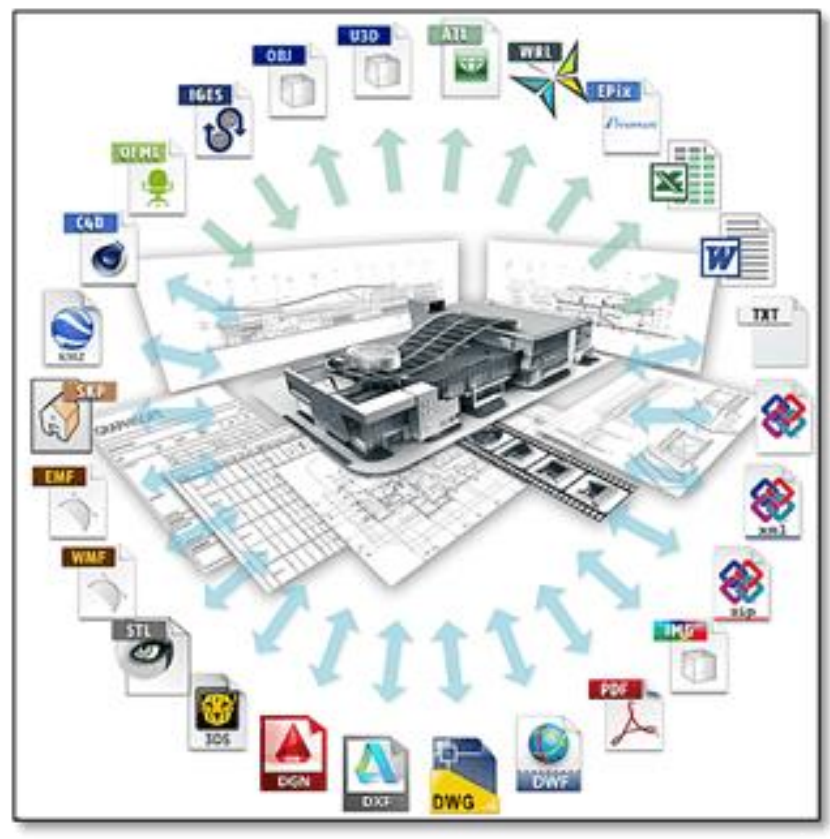

Fonte: FARIAS (2013)

De acordo com Farias (2013), a partir de 2021, por exigência do Governo Federal no decreto 10.306 de 02 de abril de 2020 (obrigatório usar BIM em obras de órgãos públicos), a modelagem em 3D será de âmbito obrigatório na Engenharia Civil e Arquitetura, com meta de que $50 \%$ do PIB da construção civil aplique a tecnologia até 2024. Segundo a Agência Brasileira de Desenvolvimento Industrial - ABCI (2019), prospera-se com o uso do BIM um aumento de $10 \%$ na produtividade e redução de custos que podem chegar a $20 \%$ ao ano.

O escaneamento em 3D, Muller (2015), permite fazer um levantamento topográfico do lote, formando uma visão tridimensional da estrutura, quando alia-se essa tecnologia ao BIM, obtêm-se uma visão mais precisa e certeira da obra, ajudando engenheiros, arquitetos e projetistas a formular um projeto de canteiro ideal ao lote e remediar futuros problemas de implantação. 


\subsection{SIENGE PLATAFORMAS}

Segundo AEBWEB (2020), a Sienge é uma plataforma de software criada pela Softplan/Poligaph, lançada para auxiliar em diversos processos dentro de um canteiro de obras.

Dentre as inovações atribuídas a essa ferramenta, Carlos Augusto de Matos, diretor da Unidade Indústria da Construção na Softplan/Poligraph ressalta o Diário de Obras, que proporciona ao empreiteiro um acesso móvel, através de aparelhos eletrônicos como tablets e smartphones, aos registros de obras atualizados (AECWEB, 2020)

O Sienge possibilita a organização de diferentes bancos de dados de insumos e serviços empregados em suas obras, permitindo a criação de composições próprias ou composições de referências (SIENGE, 2019). A plataforma tem como objetivo:

- Maior controle na criação de insumos, com preços diferenciados de acordo com marcas e detalhes;

- Organização dos insumos e serviços por grupos, facilitando a atualização de preços e a análise em relatórios;

- Administração dos preços de seus insumos segundo as atualizações e os preços abordados no setor de Compras ou Suprimentos;

- Importação de dados de insumos, serviços e composições de tabelas, sejam próprias ou de referências;

- Importação das tabelas SINAPI interligadas com o site da Caixa Econômica Federal.

\subsection{REALIDADE AUMENTADA}

Segundo Sherman e Craig (2003), a realidade virtual aumentada é um conjunto de simulações interativas geradas em computadores para obter-se a sensação de estar mentalmente e fisicamente imerso em simulações de empreendimentos futuros, proporcionando ao usuário uma abrangência informacional digital. 
De acordo Souza (2019), o capacete inteligente de realidade aumentada usual $D A Q R I$ Smart Helmet visualiza projetos e modelos 3D em grandes escalas, comparando o trabalho real com o projeto original da obra, gerando um fluxo totalmente digital entre funcionário e o escritório. A Figura 3 mostra a utilização do Capacete Daqri Smart Helmet.

Figura 3: Capacete $D A Q R I$ Smart Helmet

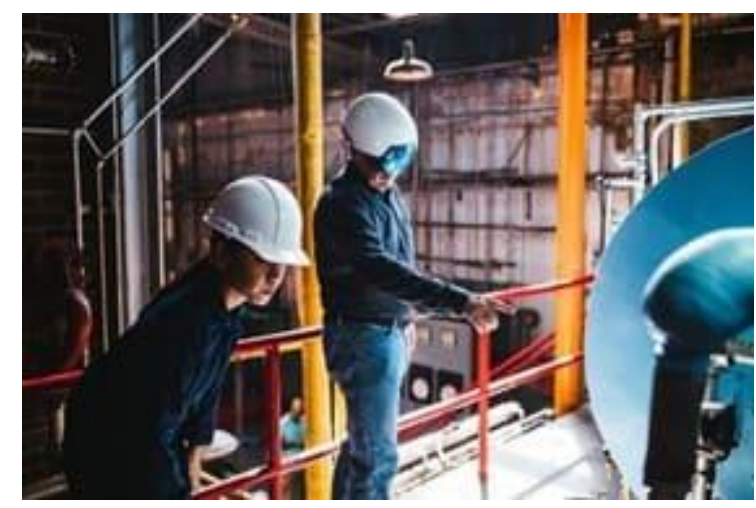

Fonte: Souza (2019)

Souza (2019), também cita os aplicativos AUGMENT e GAMMA AR como plataformas de interação. AUGMENT, Figura 4, é um app que permite ao usuário visualizar o projeto em escala real 3D, disponibilizada para sistema Android e IOS e, principalmente, utilizadas por empresas de engenharia para vendas. Já o app GAMMA AR, Figura 5, permite a visualização de tubulações de água, esgoto e gás, além de sobrepor os pavimentos em 3D. 
Figura 4: Aplicativo AUGMENT

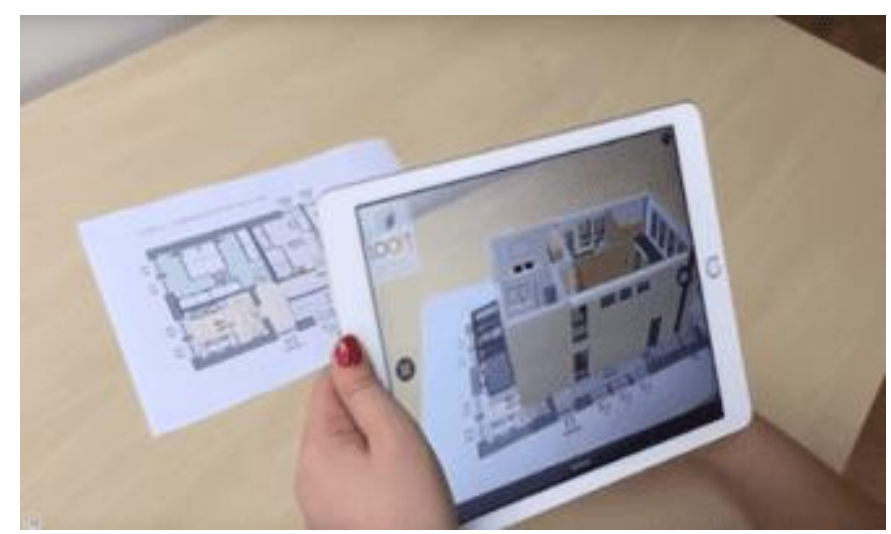

Fonte: Souza (2019)

Figura 5: Aplicativo GAMMA AR

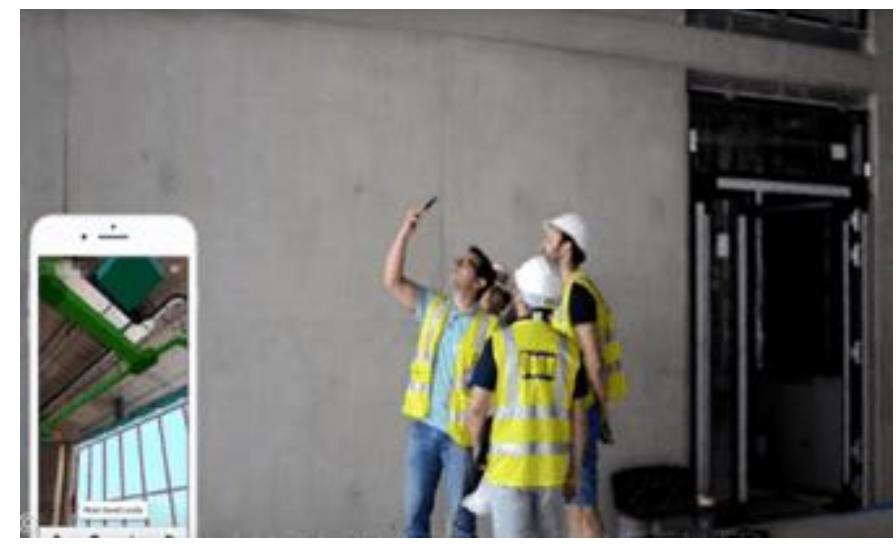

Fonte: Souza (2019)

\subsection{DRONES}

Segundo Zaparolli (2019), os drones, pequenas aeronaves que foram criadas em meio militar e hoje se popularizaram, podem medir o perímetro da construção, transmitir coordenadas exatas, gerar imagens aéreas e monitorar os canteiros. Com o tempo a utilização de drones se tornou a forma mais viável de se obter imagens em tempo real das construções, além de chamar mais atenção dos clientes no ramo imobiliário.

A empresa Maply Tecnologia realiza monitoramentos e mapeamentos aéreos para que se mantenha todos os cronogramas em dia, utilizando um aplicativo para o RC: 69360

Disponível em: https://www.nucleodoconhecimento.com.br/engenharia-civil/inovacoes-tecnologicas 
gerenciamento dos canteiros, através de etiquetas de QR Code, visualizando em tablets e celulares o canteiro por completo. Segundo Maply (2020), o aplicativo otimiza o tempo de coleta de dados, reduz cerca de $90 \%$ das impressões em papeis e foca a energia em atividades essenciais.

A Figura 6 mostra um operador manipulando um drone em um canteiro de obras.

Figura 6: Drone na construção

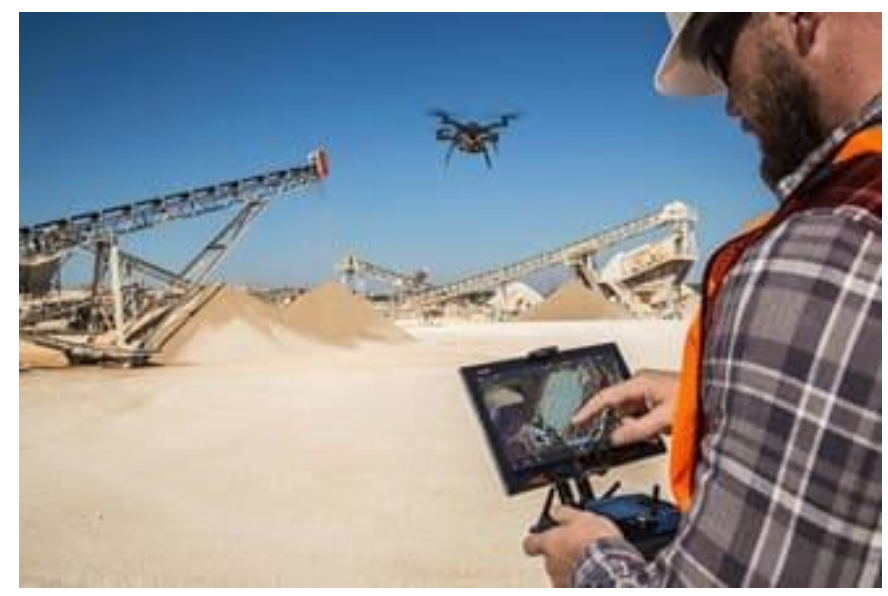

Fonte: Globaltec (2020)

\subsection{CANTEIROS VERDES}

De acordo com Gallo (2020), obras em áreas com fauna e flora geram muitos impactos ambientais e interferências no ecossistema, diante disto é possível utilizar tecnologias avançadas para a diminuição de ações que prejudicam os animais e o meio ambiente.

Segundo o Diário do Comércio (2019), a empresa Andrade Gutierrez, com mais de 70 anos de experiências em áreas ambientais, destaca-se por ser uma das maiores empresas de engenharia da América Latina que se desenvolveu de forma sustentável, priorizando a qualidade e responsabilidade socioambiental.

O S11D, em Carajás - PA, é o maior complexo minerador da história da empresa Vale, que foi construído pela empreiteira Andrade Gutierrez em 2017. A empreiteira inovou no canteiro de obras do S11D com a aquisição do VANT (veículo aéreo não tripulado), 
em que as qualidades das imagens capturadas são superiores as de drones, além de cobrir uma área vasta (ANDRADE GUTIERREZ, 2018).

Segundo Andrade Gutierrez (2020), durante as obras do Porto de Imbituba - SC, a empresa utilizou a tecnologia cortina de bolhas para impedir que os ruídos provocados pelas obras chegassem até as baleias e afetasse a comunicação dos animais, além de utilizar monitoramento via bandeiras e rádio informando a movimentação das baleias para que as obras fossem paradas.

\section{RESULTADOS E DISCUSSÃO}

Desde o início do século XXI, empresas do setor da construção civil enfrentam um momento de transição, evidenciado por consumidores mais exigentes, maior concorrência e descrédito de organizações. Nesse cenário, as instituições necessitam priorizar a melhoria na qualidade das edificações, modernização de processos e na inovação, que leva ao desenvolvimento de novos produtos (SALLES, 2013; POTT; EICH; ROJAS, 2017; PEREIRA; ALENCAR, 2019).

Pereira e Alencar (2019) afirmam que investir em tecnologia é essencial para esses três quesitos - a melhoria da qualidade, modernização e inovação - pois viabiliza o desenvolvimento e emprego de materiais e processos modernos e inovadores. Isso gera construções de maior qualidade, erguidas através de projetos ágeis e com custo reduzido.

Considerando que o setor da construção civil compreende uma gama de serviços que requer uma equipe diversificada de profissionais, serviços e materiais que atendam a demanda do setor, a pesquisa evidencia que muitos avanços ocorreram desde a Terceira Revolução Industrial transformando o setor construtivo que atualmente dispõem de um acervo tecnológico que contribuem na rapidez e qualidade da produção.

Com o passar dos anos, nas organizações, o processo de trabalho, principalmente na construção civil, vem sofrendo mudanças grandiosas que acabaram por afetar 
sensivelmente o homem (CHIAVENATO 2008, p. 479 apud FONSECA; GONÇALVES; RODRIGUES, 2012).

De acordo com Balwin (2020), o volume de produção maximizando a velocidade de trabalho é um fator com maior atribuição de aumento de acidentes de trabalho. Neste contexto, o exoesqueleto da The Guardian XO da empresa SARCOS, pode contribuir com a área da construção civil, pois o peso do traje e as cargas transportadas são transferidos através da estrutura do exoesqueleto para o chão. A empresa Sarcos diz que o equipamento contém um "conjunto de sensores integrados ao exoesqueleto, permitindo que o operador controle intuitivamente o robô de uma forma que aproveite seus instintos e reflexos e minimize a necessidade de treinamento humano". Assim, o referido robô é capaz de amplificar a força humana na proporção de 20 para 1, um saco de cimento de $50 \mathrm{~kg}$ representará $2,5 \mathrm{~kg}$ para quem estiver operando o dispositivo.

Segundo Manzione e Melhado (2014), o BIM ainda está em um estágio inicial no Brasil e as equipes permanecem trabalhando de maneira individual e com trocas de informação somente nos momentos de eventos-chave de compatibilização. Na prática continua-se trabalhando de forma convencional, o que torna a fase de execução do projeto um trabalho árduo no que se refere a planejamento, controle da obra, levantamento dos quantitativos de material, orçamento, entre outros.

De acordo com Formoso (2001), as deficiências no planejamento e controle estão entre as principais causas da baixa produtividade do setor, das suas elevadas perdas e da baixa qualidade de seus produtos.

Por se tratar de uma tecnologia de modelagem onde tem objetivo de trabalhar de forma internada, não é o que ocorre em grande parte de projetos, como Manzione e Melhado (2014), afirmam "ainda está em um estágio inicial", não são todas construtoras que possuem uma equipe BIM, e também é representada por uma pequena fatia do mercado. 
Horngren et al. (1990) identificam o sistema de gestão de custos com uma estrutura que organiza os dados e as informações de custo das empresas, no qual apresenta como atribuições fundamentais, as estimativas dos custos para produtos e serviços, disponibilizando aos gestores informações relevantes para a tomada de decisões associadas ao presente e ao futuro. De acordo com Berliner e Brimson (1998), o BIM consiste num conjunto de princípios, métodos e ferramentas para apoiar a tomada de decisões gerenciais e avaliar oportunidades.

E uma das ferramentas que se destacam e precisa ser comentada é a Sienge Plataformas que auxilia diversos processos na engenharia civil nos canteiros de obras, tornando o trabalho mais objetivo, maximizando processos e diminuindo custos.

Segundo Barducco e Constâncio (2019), com o avanço das tecnologias vem surgindo diversos mecanismos de gestão, que auxiliam todos os setores das organizações. Em se tratando do planejamento, softwares como a plataforma Sienge, entregam ao cliente toda a estrutura necessária para a elaboração dos orçamentos, gestão dos suprimentos, compras, vendas e relacionamento com os clientes, financeiro e controle de qualidade, que separados por módulos, pode ser composto de acordo com a necessidade do usuário.

Outros softwares encontram-se disponíveis no mercado e auxiliam a equipe de projeto na elaboração do planejamento, como o "Cote Aqui", que auxilia o usuário na tomada de decisão quanto à escolha dos fornecedores para compras; o "Gerencia Obra", que, em relação ao planejamento, auxilia o usuário na elaboração do orçamento, cadastro de fornecedores, financeiro, gestão de suprimentos, análogo ao método do Sienge (SIENGE, 2019).

Conforme entendimento de Thomé (2019), a realidade aumentada insere elementos digitais na realidade física. Por exemplo, a partir de uma filmagem de uma sala vazia, um aplicativo pode ser capaz de inserir cores de tintas nas paredes para que o usuário possa analisar como ficaria tal escolha, antes de executá-la. 
A modelagem 3D utiliza softwares para criar uma representação matemática de uma forma tridimensional. Alves (2018) afirma que alguns softwares de modelagem permitem que os modelos 3D sejam compartilhados e visualizados em qualquer lugar, principalmente no canteiro de obras. Dessa forma, o projeto pode ser alterado ou atualizado em tempo real, dados e cálculos imprecisos podem ser precipitadamente corrigidos e a empresa evita o retrabalho em várias etapas que acabariam gerando custos extras e atrasos na execução.

Segundo Barducco e Constâncio (2019), os aplicativos de comunicação centralizada, nas fases iniciais do projeto, são úteis para agilizar a documentação necessária, organizar e gerar relatórios em poucos segundos. Tal procedimento mantém as informações e documentos reunidos e armazenados na nuvem com segurança e disponibilidade a todos os interessados no projeto.

Para Moraes (2018), buscar formas cada vez mais ágeis e eficazes de gerenciamento de projetos é o próprio negócio da empresa. Em todo o ciclo de gerenciamento de projetos, consegue-se reduzir de $25 \%$ a $35 \%$ o volume de horas trabalhadas, chegando até a 50\%, dependendo do tipo de projeto, utilizando o software Construct App.

De acordo com Thomé (2016), o projeto ideal realizado em BIM agrega todas as partes envolvidas no planejamento de uma construção, concedendo informações detalhadas sobre cada etapa de construção e disponibilizando para todos os envolvidos. Além de facilitar dados como dimensões de paredes e localização de canos, fornece informações relacionadas a tipos e quantidades de insumos e mão de obra, por exemplos.

A autora ainda afirma que o BIM se assemelha à modelagem 3D, porém com a aplicação da nova tecnologia são adicionadas outras informações que só o BIM proporciona. Por exemplo, é possível adicionar informações sobre materiais, custos e outras especificações (THOMÉ, 2016). 
Porto (2016) mostra que trabalhando com a tecnologia BIM o projetista pode definir quantos parâmetros que ele achar necessário e visualizar com clareza as vistas do projeto. No caso de uma parede, além da espessura e altura, define-se os materiais empregados, as camadas de revestimento, o acabamento, fabricantes, propriedades termo acústicas e qualquer outra informação que se deseje adicionar. Além disso, devido a estrutura parametrizada, com poucos cliques é possível gerar plantas em 2D, e qualquer alteração no modelo principal é automaticamente atualizada para as plantas e vistas em 2D.

Segundo Muller (2015), na prática atual ainda é comum ter diversas partes do projeto, como arquitetura, instalações e estrutura, sendo desenvolvidas por equipes diferentes em separado. A falta de compatibilidade entre os projetos exige que outra equipe faça a integração, para que não haja interferências nos projetos. Este fato não garante que desperdício de matérias e recursos humanos ocorra quando se observa necessidade de fazer modificações em estruturas e componentes já executados. Já o BIM oferece uma plataforma versátil que reuni todas as informações inerentes ao projeto em um mesmo modelo central, onde cada equipe pode alterar apenas o seu escopo, cortando a etapa de compatibilização e servindo como histórico após o projeto ser terminado.

De acordo com Barducco e Constâncio (2019), a implementação do BIM demanda um investimento para novas habilidades e recursos de mão de obra de todos os profissionais envolvidos no empreendimento, como a proposta é manter tudo conectado e compatibilizado, se faz necessário planejar em conjunto. Dessa forma, toda a cadeia de profissionais deve estar ajustada ao novo método.

Neste contexto, Gonçalves Junior (2019) afirma que sua aplicação, gestão e uso das informações do modelo, proporcionam diversos usos além do projeto, como planejamento, orçamento, sustentabilidade e operação das edificações. O BIM apresenta as seguintes definições, 2D; 3D; 4D; 5D; 6D; e 7D, de acordo com o autor.

O BIM 2D, para representação ou documentação de pranchas, apresenta desenhos tradicionais em duas dimensões, com pranchas e detalhes. O modelo paramétrico 3D, gera um protótipo virtual da edificação, possibilitando assim, uma análise da 
interferência entre os elementos, antecipando imperfeições e trazendo soluções para uma execução mais assertiva. O conceito 4D associa o modelo elaborado anteriormente ao cronograma da obra, vinculando tarefas ao tempo e concebendo um planejamento visual de andamento da obra, permitindo a todos os profissionais acompanhar o avanço físico de cada etapa em tempo real. Após associar o modelo projetado ao planejamento, na definição de BIM 5D, pode-se adicionar aos elementos informações dos custos da obra, evitando surpresas e contando com informações pertinentes para auxiliar na tomada de decisões. Com um modelo rico em informações, o BIM 6D trata da sustentabilidade durante o processo de concepção de um edifício, avaliando os resultados e o impacto técnico e financeiro de forma rápida e econômica. Por fim, o BIM 7D concebe informações de término de obra, facilitando a possibilidade de manutenções, verificação de equipamentos, garantia de fabricantes e especificações técnicas. Dessa forma, os gestores da edificação podem compartilhar informações com empresas que prestam serviços mesmo após o fim da obra (GONÇALVES JUNIOR, 2019).

Os drones, veículos aéreos não tripulados e controlados à distância por controle remoto, que podem ser muito benéficos no mapeamento da área a ser construída, como parte do estudo inicial de um empreendimento. Com tal tecnologia, pode-se registrar por vídeo e fotos toda a área a ser analisada, úteis para simular projetos com o auxílio de tais imagens. Utilizam-se os drones também para comandar veículos autônomos, por meio de ferramenta mobile. O equipamento permite fazer estudos de nivelamento, que dão uma visão da movimentação de terra no terreno, podendo ser útil no grupo de atividades de iniciação (SIENGE, 2019).

De acordo com Barducco e Constâncio (2019), a maior aplicabilidade dos drones na construção civil está no auxílio ao monitoramento no canteiro de obras. Tal equipamento possibilita a inspeção em locais altos, de difícil acesso, substituindo a ação humana, reduzindo os riscos com acidentes de trabalho e os custos com equipamentos de proteção individual e coletivos, guindastes, cordas, etc.

Além disso, Thomé (2018) declara que são equipamentos úteis na fiscalização no dia a dia do andamento da obra. Com ele é possível monitorar a produtividade dos 
funcionários, a adequação dos mesmos com os equipamentos de segurança, racionalizando o uso de recurso humano para tal finalidade, podendo otimizar a mão de obra em outra atividade.

A realidade aumentada pode ser usada, segundo Barducco e Constâncio (2019), para apresentar ao cliente uma amostragem digital de como ficará a obra, após concluída. No caso de uma reforma, a tecnologia permite que o cliente visualize o resultado final dentro do ambiente físico que a reforma será executada. Um exemplo é o aplicativo Augment, que projeta, através de um tablet, uma imagem 3D de uma planta baixa impressa, em escala correta, possibilitando uma melhor visualização do projeto, sem custos com prototipagem, por exemplo.

Já para Lima (2019), o uso de realidade aumentada na execução da obra proporciona uma visão mais exata do que será construído. Por meio de plantas 3D e hologramas, é possível compreender melhor o projeto, facilitando sua execução.

Melhado (2019) diz que para um canteiro de obras ser considerado sustentável não basta apenas o planejamento e programação das medidas ambientais, sociais, econômicas, educacionais e culturais. Além disso, é necessárias essas medidas estarem presentes no dia a dia da obra. A autora anda cita ações capazes de contribuir no processo da implantação de um canteiro sustentável, tais como: o Projeto de Gestão Ambiental; a compra responsável; a relação com a comunidade; a garantia da saúde e da segurança ocupacional; o Projeto de Gestão da Qualidade; a redução das perdas de materiais; a gestão de resíduos sólidos; a utilização e a ocupação do solo (implantação do canteiro de obras); a redução do desperdício de água; a redução do consumo de energia e transporte; a conservação de fauna e flora local e a educação ambiental dos colaboradores.

\section{CONSIDERAÇÕES FINAIS}

A globalização gerou impactos significativos no modo de produção no segmento da Construção Civil, como o aumento da eficiência no uso dos recursos disponíveis, a mudança na forma de levantamento de dados e a própria forma de execução dos 
processos, com expressiva introdução de máquinas com inteligência artificial nas ações hoje executadas por humanos. Houve uma expressiva modificação também na gestão empresarial, especialmente no que diz respeito à estratégia de implementação das novas tecnologias, que exige cooperação entre todos os setores das empresas, mas, principalmente, entre as áreas de tecnologia da informação e a execução das obras.

Esse avanço tecnológico resulta em um ambiente de negócios cada vez mais dinâmico e acelerado, no que diz respeito às mudanças. Para que se mantenham competitivas no mercado, as empresas precisam adotar um efetivo gerenciamento de projetos. Para isso, tecnologias que alcançam todos os grupos de processo do gerenciamento de projetos estão emergindo, sendo de grande importância para auxiliar a execução das tarefas do ciclo de vida do projeto, como foi mencionado no presente trabalho, que cumpriu seu objetivo, apresentando algumas das ferramentas que vão colaborar com o aumento da eficiência, eficácia e efetividade dos projetos desempenhados pela Indústria da Construção Civil nos próximos anos.

Portando, como sugestão de continuidade, pode-se explorar a necessidade de mudança no perfil do profissional que atuará no segmento da Construção Civil nos próximos anos, exigido por meio de todas as transformações já sofridas, quebrando os paradigmas da formação trazida pelas universidades atualmente, que deverá passar de um profissional focado nos conhecimentos advindos da sua formação para a adoção de um perfil multidisciplinar. Isso corrobora com o estudo realizado por Oliveira e Serra (2017) quando afirmam que as contribuições para a continuidade de novas pesquisas são abrangentes e que o uso de tecnologia neste segmento só tende a crescer. Além disso, seria interessante apresentar o desenvolvimento do Brasil em relação ao mundo no setor de tecnologia e as vantagens de inovar.

\section{REFERÊNCIAS}

$\mathrm{ABCl}$. Agência Brasileira de Desenvolvimento Industrial. Construção Civil mais inteligente, produtiva e econômica. 2019. 
AECWEB. Novas tecnologias invadem canteiros de obras. 2020. Disponível em: https://www.aecweb.com.br/revista/noticias/novas-tecnologias-invadem-canteiros-deobras/7140. Acesso em Out 2020.

ALVES, N. 5 maneiras como a tecnologia na construção civil transforma a produtividade. Construct, 17 jan. 2018.

ANDRADE GUTIERREZ. Usina do Complexo S11D. 2018. Disponível em: https://www.andradegutierrez.com.br/Projetos/UsinaComplexoS11D.aspx. Acesso em Out 2020.

AUTODESK. Ajuda do Autodesk Navisworks Simulate. 2020.

BARDUCCO, A.P.S.; CONSTÂNCIA, B.M. Indústria 4.0: tecnologias emergentes no cenário da construção civil e suas aplicabilidades. Trabalho de Conclusão de Curso apresentado ao Curso de Engenharia Civil da Universidade do Sul de Santa Catarina. 2019.

BALWIN, E. Esqueletos robóticos podem ajudar os trabalhadores da construção civil a partir de 2020. Archidaily Brasil. 2020.

BERLINER, C.; BRIMSON, J. Cost management for today's advanced manufacturing. Boston: Harvard Business School, 1998.

BOCCATO, V. R. C. Metodologia da pesquisa bibliográfica na área odontológica e o artigo científico como forma de comunicação. Rev. Odontol. Univ. Cidade São Paulo, São Paulo, v. 18, n. 3, p. 265-274, 2006.

BRASIL. Ministério do Trabalho. Redação dada pela Portaria MTPS n. 3.751, de 23 de novembro de 1990. NR 17 - Ergonomia (117.000-7) Portaria N.o 876, de 24 de Outubro de 2018. Altera Norma Regulamentadora NR-17- Ergonomia. Página 2239 do Judiciário do Tribunal Regional do Trabalho da 12a ${ }^{\mathrm{a}}$ Região (TRT-12) de 16 de Agosto de 2018 
CHIAVENATO, I. Treinamento e desenvolvimento de recursos humanos: como incrementar talentos na empresa. 7.ed. São Paulo: Atlas, 2008.

DIÁRIO DO COMÉRCIO. TAG: Andrade Gutierrez. 2019. Disponível em: https://diariodocomercio.com.br/tags/andrade-gutierrez. Acesso em Out 2020.

FARIAS, J. Estudo de Viabilidade Técnica e Econômica do Método Construtivo Light Steel Framing numa Residência Unifamiliar de Baixa Renda. Projeto de Graduação, UFRJ, Escola Politécnica, Curso de Engenharia Civil, Rio de Janeiro, 2013.

FONSECA, A.B.; GONÇALVES, G.H.V.; RODRIGUES, C.L.P. Segurança do Trabalho na Construção Civil: Projeto de Pesquisa. Faculdade Evangélica De Goianésia - Curso de Administração. Goianésia. 2012.

FORMOSO, T. C. Planejamento e controle da produção em empresas de construção. Porto Alegre: Universidade Federal do Rio Grande do Sul. 2001.

GALLO, J.V. Sustentabilidade começa no canteiro de obras. AECweb. 2020.

GLOBALTEC. Drones na construção civil para otimizar obras. 2020. Disponível em: $\quad$ https://www.globaltec.com.br/2018/12/25/drones-na-construcao-civil-paraotimizar-obras. Acesso em Out 2020.

GONÇALVES JUNIOR, F. BIM: Tudo o que você precisa saber sobre esta metodologia. Mais Engenharia. 2019.

HORNGREN, C.T; FOSTER, G, SRIKANT, M.D. Cost accounting: a managerial emphasis. 7th ed. Englewood: Prentice-Hall, 1990.

IBGE. Instituto Brasileiro de Geografia e Estatística. Pesquisa Anual da Indústria da Construção. 2020.

LIMA, T. Realidade aumentada na Construção Civil. Blog Siebge. 2019. 
MANZIONE, L., MELHADO, S. Nível de maturidade do processo de projeto: as quatro interfaces. XV Encontro Nacional de Tecnologia do Ambiente Construído, AL, Maceió, 2014.

MAPLY. Dados aéreos a serviço do seu negócio. 2020. Disponível em: https://www.maply.io/industrias/enterprise-solutions. Acesso em Out 2020.

MELHADO, R.G. Canteiro de obra sustentável: estudo de empreendimento do município de Araraquara/SP. Artigo apresentado no Curso de Engenharia Civil da Universidade de Araraquara - Uniara. 2019.

MERCADO, L.P.L.; KULLOK, M.G.B. Tendências na utilização das tecnologias da informação e comunicação na educação. UFAL, 2004.

MORAES, R. Conheça a Metroll. Construct. 2018.

MULLER, L. Utilização da Tecnologia Bim (Building Information Modeling) Integrado a Planejamento 4D na Construção Civil. Projeto de Graduação, UFRJ, Escola Politécnica, Curso de Engenharia Civil, Rio de Janeiro, 2015.

OLIVEIRA, V.H.M.; SERRA, S.M.B. Controle de obras por RFID: sistema de monitoramento e controle para equipamentos de segurança no canteiro de obras. Ambiente Construído, Porto Alegre, v. 17, n. 4, p. 61-77, out./dez. 2017.

PEREIRA, A.R.; ALENCAR, E.A.B. Análise do uso das novas tecnologias na construção civil. Artigo apresentado no Curso de Engenharia Civil do Centro Universitário do Norte - Uninorte. 2019.

PORTO, T.M.S. Estudo dos avanços da tecnologia de impressão $3 \mathrm{~d}$ e da sua aplicação na construção civil. Projeto de Graduação apresentado ao Curso de Engenharia Civil da Escola Politécnica da Universidade Federal do Rio de Janeiro. 2016. 
POTT, L.M.; EICH, M.C; ROJAS, F.. Inovações tecnológicas na construção civil. In: XXII Seminário interinstitucional de ensino, pesquisa e extensão. Universidade de Cruz Alta - UNICRUZ. 2017.

SALLES, C.M.C. Aprendizagem significativa e as novas tecnologias na educação a distância. Projetos e Dissertações em Sistemas de Informação e Gestão do Conhecimento, v. 2, n. 1, 2013.

SHERMAN, W.; CRAIG, A. Understanding virtual reality. San Francisco: ed. Morgan kaufmann, 2003.

SIENGE. Drones na Construção Civil: 7 aplicações diretas na obra. Blog Sienge. 2019.

SOUZA, R.F. Inovações Tecnológicas na Construção Civil. Trabalho de Conclusão do Curso apresentado à Escola Politécnica, Universidade Federal da Bahia, Salvador, 2019.

SOUZA, D.A.; GUIMARÃES, P.V.; PERUZZI, A.P. Qualidade, segurança e eficiência de canteiros de obras. Engenharia Civil UM. n.46, 2013.

TECHNE. Planejamento Modelado. Ano 22, Edição 213. Página 34 a Página 40. Dez de 2012.

THOMÉ, B.B. O que é BIM? Entenda agora o conceito e suas aplicações. Blog Sienge. 2016.

PINI: Impressão 3D na construção: em breve uma realidade em escala. Blog Pini. 2018.

5 tendências tecnológicas que resultam em inovações na Construção Civil. Blog Sienge. 2019.

ZAPAROLLI, D. Canteiros de obra high tech. Engenharia Inovação Tecnologia. Edição 278. abr. 2019 
Enviado: Dezembro, 2020.

Aprovado: Dezembro, 2020. 